\title{
A PERCEPÇÃO DE ALUNOS DO 4. ANO DO ENSINO FUNDAMENTAL DO MUNICÍPIO DO RIO DE JANEIRO SOBRE INSETOS COMO BASE PARA A FORMULAÇÃO DE UM CURRÍCULO DE ENTOMOLOGIA
}

\author{
THE PERCEPTION OF STUDENTS OF THE 4 TH YEAR OF FUNDAMENTAL \\ EDUCATION IN THE MUNICIPALITY OF RIO DE JANEIRO ABOUT INSECTS AS A \\ BASIS FOR THE FORMULATION OF AN ENTOMOLOGY CURRICULUM
}

\section{Luiz Ney d'Escoffier ${ }^{1}$}

\begin{abstract}
RESUMO: Popularmente, os insetos são relacionados a doenças, ditos nojentos, nocivos ou perigosos e animais que não pertencem a esta classe são confundidos com eles. Para a definição de metas visando a eliminação destes preconceitos, é preciso inteirar-se dos conhecimentos prévios sobre insetos. Nosso objetivo foi levantar que conhecimentos, conceitos e influências alunos do $4 .{ }^{\circ}$ ano do ensino fundamental de escolas públicas da cidade do Rio de Janeiro possuem sobre insetos. Através de um questionário, concluímos que conhecem pouco, não conseguem distingui-los de outras classes de animais, trazem conceitos negativos e agressivos reproduzindo concepções familiares. Propomos que ao elaborar um currículo de entomologia as percepções dos alunos sejam consideradas, já que são influenciadas pelas concepções culturais.
\end{abstract}

Palavras-chave: percepção entomológica, currículo, ensino fundamental, Etnobiologia.

ABSTRACT: Popularly, insects are related to diseases, said to be disgusting, harmful, or dangerous and animals that do not belong to this class are mistaken with them. For the elimination of the existing prejudgment, it is necessary to know the level of prior knowledge so that goals can be defined in this sense. The objectives of this work were to survey what $4^{\text {th }}$-grade students from elementary school of public schools in the city of Rio de Janeiro know about insects, what concepts they bring about them, and what may be influencing this judgment. Through a questionnaire, we conclude that they know little, cannot distinguish them from other classes of animals, and bring negative and aggressive concepts reproducing the familiar conceptions. We propose that at the time of elaborating an entomology curriculum, student perceptions should be taken into account since they are influenced by cultural conceptions.

Keywords: entomological perception, curriculum, elementary school, ethnobiology

\footnotetext{
${ }^{1}$ Formado em Biologia, possui mestrado em Ciência, Tecnologia e Educação pelo Centro Federal de Educação Tecnológica Celso Suckow da Fonseca (CEFET/RJ). Atualmente é tecnologista sênior do Instituto Oswaldo Cruz, Fiocruz. Possui experiência na área de bioquímica e biologia molecular de parasitos e atualmente desenvolve pesquisas na área de educação nos seguintes temas: gamificação, utilização do lúdico no processo ensino/aprendizagem, novas tecnologias para o ensino, inovações nas escolas e PBL.E- mail: lescof@gmail.com.
} 


\section{INTRODUÇÃO}

Uma representação pode ser definida como imagens, ideias ou pensamentos presentes em nossa consciência que traduzem alguma coisa, material ou não. Assim, as representações sociais consistem no conjunto de representações geradas como resultado da interação social cotidiana. Portanto, são comuns a um determinado grupo de pessoas, correspondendo ao conhecimento produzido socialmente a partir da realidade daquele conjunto social.

Por outro lado, o conceito de representação está inter-relacionado com a percepção. Esta é a composição e interpretação de sensações sobre alguma coisa resultando em uma consciência de si e do meio ambiente (MATOS; JARDILINO, 2016). São as associações que fazemos com nosso passado, seja através de palavras, pessoas, lugares ou objetos que sentimos o mundo e nós mesmos para então redefinir conceitos (MERLEAU-PONTY, 199I). Ou seja, a percepção é sensorial, segundo este autor. Já Castoriades (1999) discorda, alegando que o entendimento do real depende do imaginário, pois os sentidos são lidos e direcionados pelas referências contidas no racional humano. Portanto, é a interpretação do mundo, um processo mental a partir do contato da pessoa com o ambiente que se dá através de mecanismos cognitivos.

As representações sobre insetos não seriam diferentes das demais, ou seja, produto sociocultural de um povo. Como os insetos estão presentes no cotidiano das pessoas é natural que, de acordo com a cultura de cada um, a estes animais sejam conferidos diferentes significados e funções (SILVA; COSTA NETO, 2004; COSTA NETO; MAGALHÃES, 2007). A etnoentomologia é um ramo da entomologia que investiga como as diferentes populações percebem, classificam e utilizam estes artrópodes (POSEY, 1987). Estes conhecimentos, frutos de experiências acumuladas e trocas de informações, são herdados pela tradição oral por gerações. Costa Neto (2003) em sua tese de doutorado realizou um profundo estudo etnoentomológico no povoado da Pedra Branca, município de Santa Terezinha, interior da Bahia. Talvez pela origem indígena e atividade de subsistência agrícola, a população possui uma percepção sobre estes animais peculiar, a qual o autor subdividiu em três dimensões. De acordo com a dimensão afetiva, as pessoas descrevem os insetos através do seu impacto negativo sobre a saúde e plantações, além de associá-los a acontecimentos benéficos ou maléficos. Já pela dimensão cognitiva, o autor observou a ideia de que os insetos podem se originar de vegetais, outros insetos ou se transformarem em outros animais. A dimensão comportamental revelou uma utilização medicinal, alimentar, estético-decorativa, mágico-ritualística e lúdica para os insetos. Ou seja, uma representação ampla e característica da sociedade local, porém nem de todo ruim. A questão é que nos meios urbanos, ideias difundidas nos meios de comunicação, escolas e produções culturais, muitas vezes contribuem para uma imagem 
pejorativa, equivocada e distorcida sobre estes animais, muito embora estes animais despertem interesse nas pessoas (TRINDADE; SILVA JÚNIOR; TEIXEIRA, 2012). Daí a necessidade de estimular os estudantes a pensar relacionalmente, deslocando a visão antropocêntrica para uma perspectiva de adaptação ao meio ambiente e suas relações com outros seres vivos.

É interessante observar que na cultura popular, outros animais que não pertencem à Classe Insecta, como aranhas, cobras e ratos são confundidos com insetos (POSEY, 1983; LAURENT, 1997; COSTA NETO; PACHECO, 2004). Em um estudo feito em 2009 com docentes e discentes do ensino fundamental no estado do Mato Grosso (MODRO et al., 2009), dos seres vivos percebidos como "insetos" pelos entrevistados, embora a maioria das respostas de fato pertencesse à classe Insecta (82,75\%), alguns docentes referiram-se também à Classe Arachnida (aranha, carrapato, escorpião) como sendo insetos, e as citações dos discentes incluíram também o Reino Fungi (leveduras e cogumelos) e as Classes do Reino Animalia: Amphibia (sapos), Reptilia (cobras, lagartos e lagartixa), Mammalia (ratos), Chilopoda (lacraia), Diplopoda (piolho-de-cobra e centopeia), Gastropoda (caramujo) e Oligochaeta (minhoca). Estudo semelhante foi realizado 7 anos depois e o mesmo resultado foi observado, onde o etnodomínio inseto foi constituído por outros animais que não insetos (BONFIM et al., 2016). Assim, observa-se que o papel da educação formal é o de restringir a definição de "insetos" aos artrópodes.

Sempre que falamos dos artrópodes, relacionamos os insetos à questão das doenças, como se estes fossem os atores principais dos prejuízos aos homens, além de parecerem nojentos, nocivos ou perigosos (SILVA; COSTA NETO, 2004) e quando nos referimos a aspectos positivos, no imaginário da sociedade deixam de pertencer à classe Insecta recebendo uma classificação diferente. Portanto, o desprezo, o medo e a aversão são os sentimentos atribuídos à classe. Sabendo-se que a maneira como percebemos, identificamos e classificamos o nosso entorno impacta diretamente na forma como agimos e expressamos nossas emoções, influenciando as atitudes orientadas nos seus usos nos costumes e atividades produtivas de determinado grupo, devemos nos preocupar em mudar esta forma de ver os insetos (DREWS, 2002; SANTOS-FITA; COSTA NETO, 2007).

Diante disso, a escola tem um papel fundamental. Contudo, ela aborda o assunto focando apenas em classificações sistemáticas, particularidades sobre morfologia e características gerais, sem mencionar as relações evolutivas destes animais, sua ecologia e influências para a biodiversidade do planeta.

Para Paulo Freire, só se aprende de fato quando o aluno se apodera do conteúdo. Portanto, o processo de aprendizagem sustenta-se em conceitos que precisam trazer algum significado para ele, ou seja, o que já conhece e utiliza costumeiramente. Segundo ele, este saber foi formado no seu dia a 
dia através de experiências, narrativas contadas, relacionamentos, enfim, é fruto da sua biografia que dará origem a sua identidade cultural. Para o autor, a lógica pedagógica precisa respeitar este saber popular, e utilizá-lo como base da prática educativa, uma vez que não se aprende se o novo conhecimento diverge do cenário a que o aluno está exposto. Porém, mesmo fazendo parte desta cultura, os ensinamentos não podem ser submeter-se a suas ideologias (FREIRE, 1979; 1987; 1998).

Estas ideias de Paulo Freire encontram eco em Ausubel (2003), quando este coloca que o ideal é relacionar o novo conteúdo com o prévio do aluno (aprendizagem significativa). A aprendizagem ocorre no instante em que o aluno reconstrói o que sabe e forma novos conceitos significativos, tornando-o apto a agir e reagir frente a realidade (CARRIL; NATÁRIO; ZOCCAL, 20I7). Desta forma, as informações relacionadas - o novo com o anterior - é que constroem o novo significado, ou seja, o que mais influência na aprendizagem é o que o estudante já sabe. Caso isso não aconteça, ou seja, não haja interação entre os novos conceitos e os pré-existentes na estrutura cognitiva do aluno, este armazenará o novo através de associações aleatórias, na chamada aprendizagem mecânica. Daí a importância do conhecimento das percepções que os alunos trazem a respeito de qualquer assunto, para que estas possam dialogar com os conteúdos específicos e desconstruir percepções erradas (SOUZA; PEREIRA; MOURA, 2018). Por isso, tanto a metodologia pedagógica quanto o material didático devém ser desenvolvidos de forma que experiências passadas e

conhecimentos já presentes na estrutura cognitiva dos alunos sejam considerados, partindo do senso comum para então romper com ele e apresentar o conteúdo científico, comum à sua realidade, para que o aluno possa refletir e responder problemas reais.

Para isto, inicialmente é preciso inteirar-se do nível de conhecimento dos estudantes para que metas possam ser definidas. Assim, o objetivo primordial deste trabalho foi fazer um levantamento acerca do que alunos do $4 . \circ$ ano do ensino fundamental conhecem a respeito de insetos, que sentimentos trazem em relação a eles e o que pode estar influenciando este julgamento. A partir daí, provocamos uma discussão a respeito do processo de ensino/aprendizagem da entomologia, de modo a que a ensino de entomologia se torne mais fascinante e muitos preconceitos possam ser eliminados.

\section{Metodologia}

Realizou-se um levantamento (GIL, 2017) a respeito da percepção que uma amostra composta por 50 alunos de faixa etária entre 8 a ir anos, do $4 .{ }^{\circ}$ ano do ensino fundamental da cidade do Rio de Janeiro possuía sobre insetos, no primeiro semestre de 2016. A escolha da série teve apoio na ideia de que estes alunos nunca haviam visto a matéria entomologia no currículo acadêmico. Foram 
selecionadas duas escolas da rede municipal de ensino da cidade do Rio de Janeiro, baseando-se no critério de realidades socioeconômicas distintas. A escola denominada A está localizada na zona norte da cidade, enquanto a escola denominada AF localiza-se na zona sul da cidade, região socioeconomicamente mais privilegiada. Cada estabelecimento tem apenas uma turma de $4 . \stackrel{\circ}{\text { ano, }}$ ambas com 25 alunos. O critério de inclusão dos alunos foi o aceite na participação através da assinatura dos termos livres e esclarecidos.

Um questionário estruturado abordou, de forma compatível com o grau de entendimento correspondente à série, conhecimentos básicos de entomologia, além de levantar dados a respeito da fonte dos conhecimentos que possuem sobre insetos. As perguntas pertinentes aos insetos foram estruturadas na forma de múltipla escolha, sendo permitida, para algumas questões, a marcação de mais de uma resposta. Os alunos responderam de maneira anônima em sala de aula, com a ajuda do professor titular de cada turma, e os dados foram analisados quantitativamente, tabulados em conjunto e expressos na forma de percentuais, apresentados em tabelas e histogramas para facilitar a interpretação.

O projeto referente ao presente trabalho foi aprovado pela Comissão de Ética em Pesquisa com Seres Humanos do Instituto Oswaldo Cruz/FIOCRUZ recebendo a licença n. o $^{-}$ 43502415.1.0000.5248 e também obteve autorização junto à Secretaria Municipal de Educação da Cidade do Rio de Janeiro conforme processo no 07/003.920/2015.

\section{Resultados}

Para que os resultados possam ser expostos de forma mais clara, as perguntas serão apresentadas na forma de subitens, como a seguir:

Pergunta I: Como você reconhece um inseto?

\begin{tabular}{|c|c|c|}
\hline \multirow{2}{*}{ Opções } & \multicolumn{2}{|c|}{ Escola } \\
\cline { 2 - 3 } & AF (\%) & A (\%) \\
\hline Pelo número de patas & 7,5 & 26,9 \\
\hline Pelo tamanho & 30 & 26,9 \\
\hline Pela aparência nojenta & 37 & $4 \mathrm{I}$ \\
\hline Pelo número de asas & 7,5 & $\ldots . .$. \\
\hline Pelas cores & $\mathrm{I} 8,5$ & 5,9 \\
\hline Não consigo reconhecer & $\ldots . . . .-$ & $\ldots . . .-$ \\
\hline
\end{tabular}

QUADRO I: percentuais de respostas referentes a forma de reconhecimento de um inseto

Os alunos deveriam marcar a opção que se refere ao número de patas. Entretanto, em ambas as escolas, a opção "pela aparência nojenta" foi a mais escolhida, seguida pela opção "tamanho". A opção correta também foi a segunda mais escolhida pela escola A. Porém, estes resultados 
demonstram que nas duas escolas, menos que a metade dos alunos conseguem reconhecer um inseto corretamente, escolhendo opções que refletem suas percepções acerca destes animais (nojentos e pequenos).

Pergunta 2: Quantas pernas tem um inseto?

\begin{tabular}{|c|c|c|}
\hline \multirow{2}{*}{ Opções } & \multicolumn{2}{|c|}{ Escola } \\
\cline { 2 - 3 } & $\mathrm{AF} \mathrm{( \% )}$ & $\mathbf{A ~ ( \% )}$ \\
\hline 8 & $\mathrm{15}$ & $\mathrm{17}, 6$ \\
\hline 6 & 19,5 & 22,5 \\
\hline 4 & 65 & 60 \\
\hline Nenhuma & $\ldots . . .-$ & $\ldots . .$. \\
\hline
\end{tabular}

QUADRO 2: percentuais de respostas referentes ao número de patas de um inseto

Quando perguntados se sabiam quantas patas tem um inseto, a grande maioria achou que os insetos possuem 4 patas. A resposta certa (6 patas) foi escolhida em segundo lugar. Este erro é bastante comum, não apenas entre as crianças, mas também na população adulta. Possivelmente, a antropoformização dos animais em geral pelos estúdios de animações cause esta indução ao erro.

Pergunta 3: Para que servem os insetos?

\begin{tabular}{|c|c|c|}
\hline \multirow{2}{*}{ Opções } & \multicolumn{2}{|c|}{ Escola } \\
\cline { 2 - 3 } & AF (\%) & A (\%) \\
\hline Produzir alimentos & $\mathrm{I} 6$ & $\mathrm{I}$ \\
\hline Transmitir doenças & 48 & 38 \\
\hline Destruir plantações & 8 & 25 \\
\hline Embelezar o ambiente & 20 & 9 \\
\hline Produzir remédios & $\ldots \ldots . .-$ & 3 \\
\hline Nada & $\ldots . . . .-$ & 3 \\
\hline Não sei & 8 & 9 \\
\hline
\end{tabular}

QUADRO 3: percentuais de respostas referentes a percepção importância de um inseto

Mesmo sendo possível marcar mais de uma opção, a vasta maioria continuou a ver os insetos como um transmissor de doenças, sendo essa opinião muito mais clara na escola AF do que na $\mathrm{A}$. Com relação as demais opções, houve divergências nas escolas. Houveram algumas marcações em "nada" na escola A e a opção "não sei” foi anotada em ambas escolas. Estes dados revelam que na escola $\mathrm{AF}$ a concentração das respostas apresentou uma dualidade, embora a visão perniciosa seja a predominante. Já na escola $\mathrm{A}$ as respostas convergiram para o caráter nocivo dos insetos. Estes entendimentos podem ser fruto da proximidade dos alunos com os insetos. Sendo os alunos de AF moradores da zona sul da cidade, de melhor condição socioeconômica, revelam uma percepção mais equilibrada com relação aos insetos, notando que, de fato, alguns destes organismos são danosos, mas também são capazes de apresentar benefícios ao embelezarem o ambiente. Os da escola A talvez 
tenham mais contato com insetos domésticos, tradicionalmente relacionados a doenças, daí a percepção ruim.

Pergunta 4: O que você faz quando vê um inseto em sua casa?

As respostas deixam clara a relação que os alunos têm com os insetos, como é possível observar no gráfico I. A opção mais marcada nas duas escolas foi "mata", seguida de "corre", "grita" e "chama alguém". Não houve nenhuma marcação na opção "acha bonito", e poucos reagiriam indiferentemente, como ficar olhando ou simplesmente não fazer nada. Estes posicionamentos refletem o temor que os escolares possuem dos insetos e a atitude primária de matar retrata inequivocamente a hostilidade gratuita a estes animais.

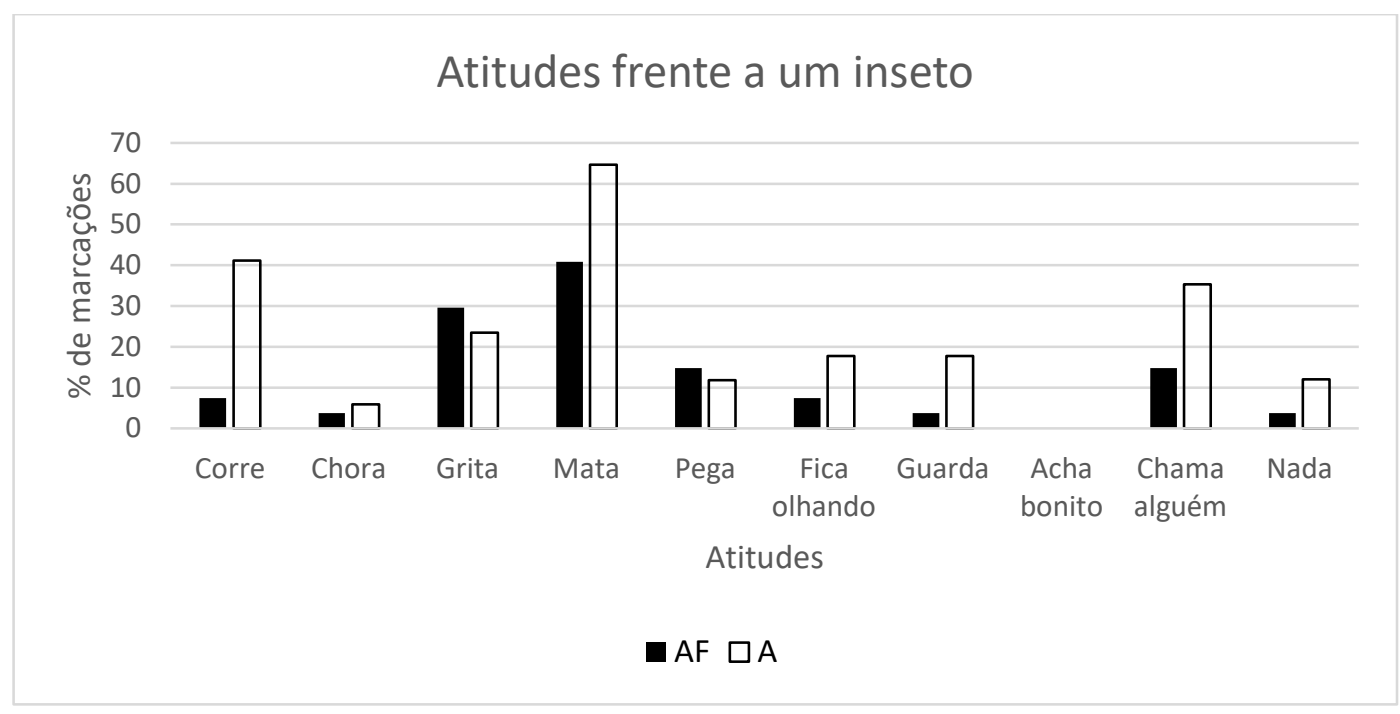

GRÁFICO r: Atitudes dos alunos quando se deparam com um inseto

Pergunta 5: Marque os insetos

Nesta questão foram apresentadas imagens, com os nomes ao lado, de vários animais, insetos ou não. $\mathrm{O}$ objetivo era os alunos marcarem aqueles que acreditavam tratar-se de insetos. Como é possível observar no gráfico 2, as duas escolas mostraram um padrão de respostas, com boa marcação nos insetos, mas houve substancial escolha de outros animais. Estes resultados eram esperados, com amplo respaldo na literatura, sendo o fenômeno detectado não apenas em crianças, mas também em alunos do EJA (Educação de Jovens e Adultos), adultos e até em docentes de áreas urbanas e rurais (BARTOSZECK; BARTOSZECK, 2or2; MONTENEGRO, et. al., 20I4; AMARAL; MEDEIROS, 
2015; LIMA et al., 2012, SILVA; COSTA NETO, 2004). Percebe-se que as escolhas foram baseadas nas características morfológicas dos animais.

Interessante notar que não existiu unanimidade nem de acertos e nem de erros. Mesmo insetos tradicionalmente conhecidos, como barata, mosquito e mosca, não foram marcados por todos os alunos. Uma hipótese para isto é que, embora o questionário tenha sido explicado em detalhes e a questão admitisse mais de uma resposta, os alunos ficaram receosos em assinalar muitas opções, deixando de lado algumas.

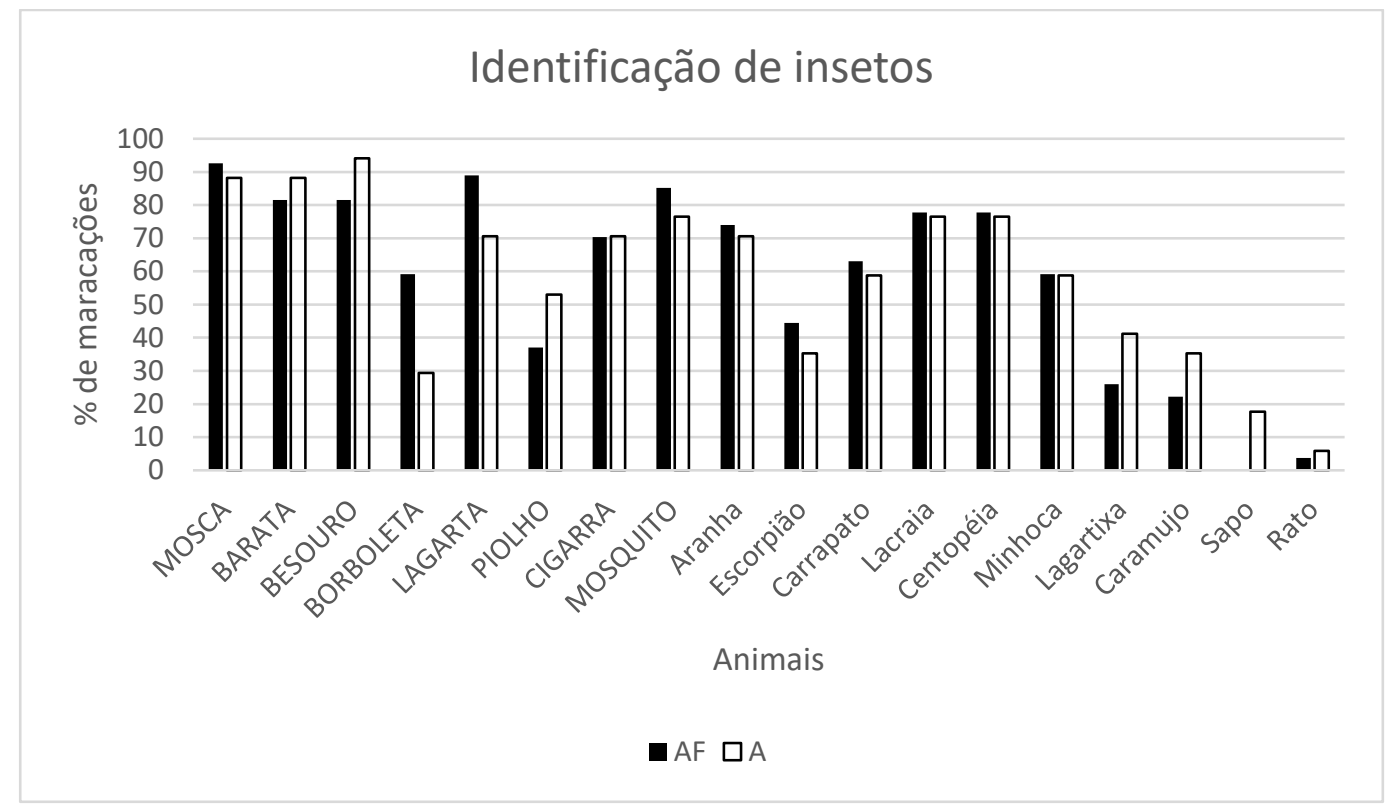

GRÁFICO 2: Identificação de animais dentro da categoria "inseto". Os animais em letras maiúsculas são insetos, enquanto que os demais não.

Pergunta 6: Como é um inseto?

\begin{tabular}{|c|c|c|}
\hline \multirow{2}{*}{ Opções } & \multicolumn{2}{|c|}{ Escola } \\
\cline { 2 - 3 } & AF (\%) & A (\%) \\
\hline Pequeno & 31 & 43 \\
\hline Perigoso & 39 & 30 \\
\hline Nojento & 25 & 27 \\
\hline Bonito & 6 & ----- \\
\hline Não sei & ----- & ----- \\
\hline
\end{tabular}

QUADRO 4: percentuais de respostas referentes a percepção de um inseto

Os alunos veem os insetos como perigosos, nojentos e pequenos. O interessante é que não houve marcações na opção "bonito" por nenhum aluno da escola $\mathrm{A}$, embora muitos tenham usado esta expressão quando viram a imagem de um inseto quando apresentada em outra ocasião. A opção "pequeno" foi a mais marcada pelos alunos da escola A, enquanto que a opção "perigoso" foi a mais 
escolhida pelos alunos da escola AF. A terceira opção foi "nojento" e poucos alunos da escola AF acham os insetos bonitos.

Estes dados corroboram os demais, onde os estudantes possuem aversão aos insetos porque os acham perigosos.

Pergunta 7: Quem te ensinou coisas sobre insetos?

\begin{tabular}{|c|c|c|}
\hline \multirow[t]{2}{*}{ Opções } & \multicolumn{2}{|c|}{ Escola } \\
\hline & $\mathrm{AF}(\%)$ & A (\%) \\
\hline Escola & 12 & 28 \\
\hline Colegas & -...- & -...- \\
\hline Pai, mãe, tios, avós & 46 & 50 \\
\hline Televisão & $3 \mathrm{I}$ & 17 \\
\hline Livros & .....- & -..... \\
\hline 'Internet' & ...... & -..... \\
\hline Não sei nada sobre insetos & 8 & 6 \\
\hline
\end{tabular}

QUADRO 5: percentuais de respostas referentes a fonte de conhecimentos sobre insetos

Como este segmento ainda não teve entomologia em sua grade curricular, como estes alunos adquiriram os conceitos a respeito de insetos? As respostas revelaram o papel da família como transmissores de conceitos, sendo a mais votada. A segunda e a terceira posições alternaram-se nas duas escolas: na AF, televisão foi a segunda escolhida enquanto na escola A poucos identificaram a televisão como meio de aprendizado sobre insetos, preferindo a escola. Um aluno declarou que aprendeu sozinho, mesmo que esta opção não estivesse presente no questionário.

O curioso é que opções esperadas, como colegas, livros e principalmente internet, não tiveram nenhuma marcação. Isto deve-se possivelmente ao fato de que o assunto não desperta interesse nos jovens. A fonte dos conceitos reconhecida pelos alunos apresenta-os impositivamente, enquanto para estas opções não escolhidas, é necessário um interesse preliminar que motive a busca a respostas. Este dado revela, portanto, o desprezo que estes estudantes têm para com os insetos.

\section{Discussão}

Neste trabalho foi realizado um levantamento da percepção que alunos do $4 .^{\circ}$ ano do ensino fundamental têm a respeito de entomologia. A maioria das crianças só são capazes de pensar hipoteticamente quando é dado um exemplo concreto. O pensamento formal só se desenvolve a partir dos 14 anos. Assim, quanto mais oportunidades de ensino manual e exemplos da realidade existirem no ensino fundamental, melhor (MATTHEWS; FLAGE; MATTHEWS, 1997). Neste contexto, os insetos se destacam. 
Os alunos que participaram da pesquisa ainda não haviam visto o tema entomologia academicamente. Assim, esperamos que as perguntas tenham sido respondidas de forma espontânea, revelando o saber pré-escolar, resultado das suas vivências e relações sociais apenas.

Nas questões relacionadas à percepção ficou clara a imagem que os estudantes possuem a respeito dos insetos. Quando perguntados sobre a forma de reconhecimento de um inseto, a opção "pela aparência nojenta" foi a mais escolhida, demonstrando como um inseto se apresenta no imaginário dos alunos. Da mesma maneira, os insetos são vistos como destruidores de plantações e transmissores de doenças, com uma ampla vantagem sobre a opção produtores de alimentos. Essa observação já havia sido feita por Costa Neto e Pacheco (2004) e, segundo estes autores, essa reação pode ser explicada pela hipótese da ambivalência entomoprojetiva. De acordo com esta hipótese, as pessoas projetam seus sentimentos de perniciosidade, risco, repugnância e indiferença por qualquer animal, classificando-o como inseto, ou seja, inseto é "tudo aquilo que não presta". Assim, explicase porque os insetos são vistos como pequenos e perigosos, e a reação ao ver um é matar, correr e chamar alguém, apresentadas nesta pesquisa. Não podemos deixar de destacar que, nos últimos anos, o Rio de Janeiro sofre com várias epidemias do vírus da Dengue, Zica e Chikungunya, todos transmitidos por mosquitos (BURATTINI, 2016). Portanto, precisamos considerar que estes episódios podem influenciar negativamente no juízo quanto aos insetos em geral.

É explícito o desconhecimento que os alunos possuem sobre insetos, uma vez que a maioria pensa que possuem 4 patas, provavelmente devido às referências antropomorfizadas dos filmes infantis e desenhos animados. Além disso, outros animais pertencentes a outras classes taxonômicas foram identificados como insetos. Segundo Costa Neto e Magalhães (2007), o termo "inseto" é um domínio de construção cultural que engloba diferentes grupos taxonômicos, baseado na percepção morfológica e comportamental. Por isso, na suposta realidade dos alunos, artrópodes em geral, como aracnídeos, além de anelídeos, répteis, quilópodes e até mamíferos são citados como insetos.

A maioria relatou que os conhecimentos que possuem sobre insetos provêm da família. Conforme Sousa et al. (2013), as crianças imitam as reações dos pais em resposta aos seres ao seu redor. Assim, em uma sociedade que detém sentimentos de repulsa aos insetos, é fácil a perpetuação deste pensamento, daí a importância da escola para a mudança neste parecer. Por outro lado, Guedes et al. (2016) apresenta resultados divergentes ao trabalhar com alunos do ensino médio de escolas públicas e particulares no estado da Pará́ba. Eles perceberam que a principal procedência do aprendizado sobre insetos foram a escola e os livros, enquanto a família teve pouca representatividade. Isso pode ser decorrência da faixa etária mais elevada, quando os adolescentes já não dialogam com seus familiares como antes, buscando informações em outras fontes. 
O fato de não haver referências à internet pode revelar o desinteresse no assunto, uma vez que esta fonte de dados é condicionada a uma busca relacionada à curiosidade ou necessidade do sujeito. Na falta de qualquer um destes estímulos, a internet torna-se inútil como transmissora de informação. O mesmo raciocínio se aplica aos colegas, demonstrando não ser esse um tema discutido socialmente. Assim, a percepção entomológica destes alunos não é consequência de curiosidade ou interesse, e sim da imposição feita por parentes ou por algum programa de televisão que esteja sendo veiculado no momento.

Nossos resultados são corroborados por diversos estudos realizados ao longo dos anos. De acordo com Modro et al. (2009), não apenas discentes, mas também docentes relacionam aspectos negativos aos insetos, provocando reações que vão do medo à agressividade contra estes animais (AMARAL; MEDEIROS, 2015; JUNIOR, COSTA NETO; SANTOS, 2014; SANTOS et al., 2015; CAJAIBA; SILVA, 2015). Entretanto, aparentemente, estes trabalhos são desenvolvidos em regiões e/ou cidades essencialmente rurais. O nosso trabalho, ao contrário, buscou levantar as percepções de alunos de áreas urbanas da cidade do Rio de Janeiro. Daí sua importância, ao revelar, ao que tudo indica, não haver diferenças nas concepções entomológicas entre diferentes realidades socioeconômicas na cidade do Rio de Janeiro, mas também exteriores a ela.

Para mudar essa concepção negativa, Costa Neto e Pacheco (2004) pensam ser preciso

oportunizar os alunos a ter contato direto com espécimes esteticamente atraentes, com modos de vida curiosos e, se possível, com aromas agradáveis. Silva-Júnior et al. (2004) reforçam essa ideia ao lembrar a estima que todos têm pelos mamíferos, talvez devido a representarem a maioria dos animais domésticos e sua exposição simpática na mídia.

Entretanto, o ensino de zoologia possui demasiado e acentuado enfoque antropocêntrico. Um estudo realizado por Magalhães e Mohr (2014) evidencia que os livros didáticos de ciências do ensino fundamental, integrantes do Programa Nacional do Livro Didático (PNLD), apresentam uma abordagem antropocêntrica utilitarista. Portanto, estes livros não são uteis para minorar o desprezo da população pelos insetos, ao tratá-los descontextualizadamente do ambiente, com pouca preocupação na maneira em que esta abordagem pode influenciar no ensino.

\section{Considerações finais}

Podemos concluir que os alunos da faixa etária trabalhada conhecem muito pouco acerca dos insetos, não conseguindo sequer distingui-los de outras classes de animais, possivelmente por ainda não terem visto entomologia na grade curricular, reproduzindo, portanto, as concepções familiares. Pela mesma razão, trazem conceitos negativos e agressivos relacionados, demonstrando que 
provavelmente a deficiência no ensino de entomologia venha se propagando a gerações. Também não identificamos relação entre a realidade socioeconômica e a percepção sobre insetos.

Para Perrenoud (1999), competência é "uma capacidade de agir eficazmente em um determinado tipo de situação, apoiado em conhecimentos, mas sem se limitar a eles”. Portanto, a escola deve oferecer aos alunos preparo para que sejam capazes de aplicar seus conhecimentos no enfrentamento de situações cotidianas. O conhecimento científico é essencial na vida moderna, portanto, sua presença na Educação Básica é incontestável. Essa construção de competências fundamentadas em conhecimentos é um compromisso que deve ser iniciada nos primeiros anos do ensino fundamental. Entretanto, um certo grau de especificidade é difícil para o entendimento de alunos do ensino fundamental. Contudo, se por um lado a superficialidade dos conteúdos resume as possibilidades de exploração de situações para o desenvolvimento de competências, por outro, na segunda metade do ensino fundamental e no ensino médio o nível de especialização associados ao incremento de volume e cobrança de conteúdo podem ser um obstáculo nesse processo (MACÊDO, 2009). Desta maneira, o ensino de ciências para o ensino fundamental deve procurar por meio do geral chegar no específico, através do despertar da curiosidade e de um ensino divertido. Nessa lógica, os insetos são uma excelente ferramenta pedagógica para a compreensão do equilíbrio da natureza, criando uma visão ampla em um eixo ecológico-evolutivo, ou ainda servirem como modelo para o estudo de processos comuns a qualquer ser vivo, como crescimento e reprodução. Não que outros grupos biológicos não possam ser trabalhados em especificidade, mas, os insetos levam uma vantagem devido a sua heterogeneidade, abundância e menor complexidade frente a vertebrados ou plantas, por exemplo.

Porém, o tema só terá êxito como ferramenta pedagógica se for considerada a realidade sóciocultural dos alunos e da própria escola. Logo, precisamos enxergar a escola como um ambiente multicultural, de acordo com a própria Lei de Diretrizes e Bases da Educação Brasileira (Lei n.o 9.394/96), ao enunciar logo no seu I. ㅇ artigo que "a educação abrange os processos formativos que se desenvolvem na vida familiar, na convivência humana, no trabalho, nas instituições de ensino e pesquisa, nos movimentos sociais e organizações da sociedade civil e nas manifestações culturais". Isso porque os estudantes trazem para o ambiente escolar, informações pré-existentes influenciadas pela sociedade e cultura que vivem. Por isso, é lógico acreditar que os alunos já possuem noções e experiências a respeitos dos insetos. Daí a importância de se diagnosticar os conhecimentos prévios dos estudantes antes de iniciar qualquer conteúdo novo, pois estes servirão de parâmetros para o planejamento do rumo a ser tomado (CARVALHO; BOSSOLAN, 2009). Como afirma Paulo Freire (1973), "é impossível ensinarmos conteúdos sem saber como pensam os alunos no seu contexto real, 
na sua cotidianidade. Sem saber o que eles sabem independentemente da escola para que os ajudemos a saber melhor o que já sabem, de um lado e, de outro, para, a partir daí ensinar-lhes o que ainda não sabem".

Entretanto, os conceitos e percepções dos alunos na maioria das vezes são originários da família. Caso esses conceitos familiares sejam carregados de conotações negativas, a criança irá assimilar estas visões e preconceitos que, muitas vezes, perduram além do aprendizado formal (LOPES e cols., 2013). Assim, é papel da escola incentivar o entendimento acerca destes animais para reduzir os aspectos negativos (LEON e cols., 2014) além de possibilitar o entendimento acerca do seu papel no ambiente (TRINDADE; SILVA JUNIOR; TEIXEIRA, 2012).

Então, precisamos pensar em novas estratégias que mirem a condução destas informações a horizonte onde os animais tenham uma importância maior, independente do nicho ou do habitat em que estejam. Pouco se conhece sobre as habilidades e estratégias que os insetos têm de vida da terra. A maioria dos alunos deixa de ter contato com isso em todas as disciplinas cursadas. Pouco se valoriza no ensino fundamental e médio a informação acerca da entomologia e suas nuances. A Entomologia, disciplina que só pode ser vista nas faculdades e universidades, não pode ser estudada em sua plenitude, pois está na maioria das vezes agregadas a outros conteúdos em artrópodes. O conhecimento sobre insetos deveria ser mais amplo e específico. A interdisciplinaridade é comum atualmente envolvendo a entomologia, mas ela não ultrapassa os muros universitários, não atinge as escolas e locais que tratam da biodiversidade no Brasil. Talvez o pensamento se volte para a preservação dos animais maiores, como os vertebrados, esquecendo-se da biodiversidade entomológica, essencial para o equilíbrio de teia alimentar.

Porém, o ensino de entomologia não deve e não pode considerar somente os aspectos conceituais. Como explicitado neste trabalho, as percepções dos alunos são fortemente influenciadas pelas concepções culturais, devendo, portanto, também serem consideradas no momento de se elaborar um currículo de entomologia para o ensino básico.

Como discutido anteriormente, os livros didáticos não ajudam para redução dos preconceitos contra os insetos, pois se limitam a aspectos morfofisiológicos, com abordagem demasiadamente antropocêntrica, evidenciando o maniqueísmo relacionado aos insetos (CARDOSO; CARVALHO; TEIXEIRA, 2008). Com base na aprendizagem significativa, o confronto entre os conhecimentos pregressos e os recém-adquiridos são fundamentais para que o processo de aprendizagem aconteça. Portanto, os livros didáticos precisam fazer com que os alunos se identifiquem com o conteúdo, mostrando inicialmente objetos comuns à sua realidade, para a partir dali apresentar novos conceitos que permitam uma reflexão e a criação de uma nova realidade. Devemos lembrar que os professores 
do ensino fundamental são polivalentes, não apresentando na sua grande maioria formação específica em biologia. Assim, os livros didáticos que deveriam servir como apoio às atividades de ensino-aprendizagem e auxílio ao planejamento didático, acabam se reduzindo à única fonte de conhecimento para o professor (LOPES e cols., 2013).

Aí está o desafio do professor. Para tal, sugere-se analogias de temas correlatos como água ou solo, por exemplo, com os insetos. Ou seja, interação entre o teórico e o prático, entre as definições acadêmicas e o ecossistema que circunda a comunidade em questão, isto é, o conhecimento prévio

dos estudantes. É preciso que, com a ajuda do professor, os alunos consigam identificar a contribuição destes artrópodes na manutenção do meio ambiente, polinizando, dispersando sementes ou fazendo parte da cadeia alimentar. Acreditamos que o conhecimento sobre a biologia e a ecologia dos insetos permitirá que os alunos constatem a presença deles em todos os segmentos do ecossistema e sua importância para a biodiversidade, para assim abandonar percepções inapropriadas, substituindo-as por outras embasadas cientificamente e então mudar suas relações com eles.

Embora este estudo some contribuições à literatura, existe a consciência que existem limitações. Devido ao tamanho reduzido da amostra, os resultados devem ser considerados no contexto e não generalizados. Novos estudos precisam ser realizados com a finalidade de corrigir estas limitações, tais como a utilização de outras regiões da cidade, além da inclusão de escolas particulares e outras séries, como, por exemplo, $7 .^{\circ}$ e $9 . .^{\circ}$ ano do ensino fundamental e 2.. do ensino médio.

No entanto, esta pesquisa fornece um ponto de partida, levando à discussão da importância do tema mesmo nas séries iniciais e a necessidade de reformulação dos livros didáticos, à luz de uma aprendizagem significativa. Esperamos, portanto, termos gerado um incremento de conhecimento a respeito das percepções que alunos das séries iniciais do ensino fundamental possuem sobre insetos.

\section{Agradecimentos}

Agradeço à Secretaria Municipal de Educação da cidade do Rio de Janeiro, às diretoras das escolas e, em especial, às professoras das turmas estudadas. Deixo aqui também os meus agradecimentos a todos os alunos e seus responsáveis pela participação na pesquisa.

\section{Referências bibliográficas}

AMARAL, K.O.; MEDEIROS, M.A. Análise das concepções de estudantes do ensino fundamental sobre insetos, por meio da metodologia do discurso do sujeito coletivo. Brazilian Geographical Journal: Geosciences and Humanities research medium, v.6, n. I, p. 156-180, 2015. 
AUSUBEL, D. P. Aquisição e retenção de conhecimentos: uma perspectiva cognitiva. Lisboa, Ed. Plátano, 2003.

BARTOSZECK, A.; BARTOSZECK, F.K. Educação de jovens e adultos: estudo exploratório do conceito de inseto. Estação Científica, v.2, n. ${ }^{\mathrm{o}}$ I, p. 33-41, 2012.

BONFIM, B.L.S.; FONSECA FILHO, I.C.; FARIAS, J.C.; FRANÇA, S.M.; BARROS, R.F.M.; SILVA, P.R.R. Etnoentomologia em comunidade rural do cerrado piauiense. Desenvolvimento e Meio Ambiente, v.39, p. 189-205, 2016.

BRASIL. Secretaria de Educação Fundamental. Parâmetros Curriculares Nacionais: terceiro e quarto ciclos do ensino fundamental. Brasília: MEC/SEF, 436p. 1998. Disponível em: http://portal.mec.gov.br/seb/arquivos/pdf/ttransversais.pdf.

BURATTINI, M.N. Doenças infecciosas do século XXI. Acta Paulista de Enfermagem, v. 29, n. 2, Editorial, 2016.

CAJAÍBA, R.L.; SILVA, W.B. Percepção dos alunos do ensino fundamental sobe insetos antes e após aulas práticas: um caso de estudo no município de Uruara - Pará, Brasil. Revista Lugares de Educação, v. 5, n. II, p. II8-132, 2015.

CARDOSO, J. dos S., CARVALHO, K. S.; TEIXEIRA, P. M. M. Um estudo sobre a abordagem da classe Insecta nos livros didáticos de ciências. Sitientibus: Série Ciências Biológicas, Feira de Santana, v.8, n.I, p.8o-88, 2008.

CARRIL, M.G.P.; NATÁRIO, E.G.; ZOCCAL, S.I. Considerações sobre aprendizagem significativa a partir da visão de Freire e Ausubel - uma reflexão teórica. e-Mosaicos, v. 6, no 3, p.6878, 2017.

CARVALHO, J. C. Q.; BOSSOLAN, N. R. S. Algumas concepções dos alunos do ensino médio a respeito das proteínas. In: Anais do VII Encontro Nacional de Pesquisa em Ensino de Ciência. Florianópolis: VII ENPEC, 2009.

CASTORIADES, C. Feito e a ser feito: as encruzilhadas do labirinto V. Rio de Janeiro, $2^{\underline{a}}$ ed., ed. DP\&A, 1999 .

COSTA NETO, E. M. Etnoentomologia no povoado de Pedra Branca, município de Santa Terezinha, Bahia. Um estudo de caso das interações seres humanos/insetos. Tese de doutorado apresentada ao Centro de Ciências Biológicas e da Saúde, Universidade de São Carlos, 2003.

COSTA NETO, E. M.; MAGALHÃES, H. F. The ethnocategory "insect" in the conception of the inhabitants of Tapera County, São Gonçalo dos Campos, Bahia, Brazil. Anais da Academia Brasileira de Ciências, v. 79, no 2, p. 239-249, 2007.

COSTA NETO, E. M.; PACHECO, J. M. A construção do domínio etnozoológico “inseto" pelos moradores do povoado de Pedra Branca, Santa Terezinha, Estado da Bahia. Acta Scientiarum. Biological Science, v.26, no I. p. 81-90, 2004.

DREWS, C. Attitudes, knowledge and wild animals as pets in Costa Rica. Anthrozoös: a multidisciplinary journal of the interactions of people and animals. v. I5, no 2, p. I19-138, 2002; 
FREIRE, P. Conscientização: teoria e prática da libertação. Uma introdução ao pensamento de Paulo Freire. ED. Cortez \& Moraes, 1979.

FREIRE, P. Pedagogia do oprimido. ED. Paz e Terra, 1987.

FREIRE, P. Professor sim, tia não: cartas a quem ousa ensinar. $3^{\underline{a}}$ ed., São Paulo: ED. Olho D'Água, 1993.

FREIRE, P. Pedagogia da autonomia: saberes necessários para a prática educativa. ED. Paz e Terra, 1998.

GIL, A.C. Como elaborar projetos de pesquisa. Cap. II, p. 9I-IoI, 6ª ed., ed. Atlas, 2017.

GUEDES, R.S.; SANTOS, W.S.; MEDEIROS, F.S.; ALMEIDA, A.B.M. Percepção entomológica de alunos do ensino médio da cidade de Patos, Paraíba. Revista Verde de Agroecologia e Desenvolvimento Sustentável, v. II, n⿳0 2, p. 0I-07, 2016.

JUNIOR, E.A.S.; COSTA NETO, E.M.; SANTOS, G.C.B. As concepções que estudantes da sexta série do ensino fundamental do Centro de Educação Básica da Universidade Estadual de Feira de Santana possuem sobre os insetos. Gaia Scientia, v.8, no 1, p. o8-16, 2014.

LAURENT, E. Definition and cultural representation of the category mushi in Japanese culture. Journal of Human-Animal Studies, v. 3, no 2, 1997.

LEON, R. G.; GONZÁLEZ, G. M.; VILLACORTA, A. T.; RODRÍGUEZ, C. P.; BALAM, F. C.; GÓNGORA, A. R.; MEJÍA, J. C. Aproximación y diffusion de la enfermedad de chagas en dos comunidades de Mexico por médio de colecciones entomológicas creadas com los Estudiantes de primaria. Revista de educación em biologia, v. I8, n. I, 2015.

LIMA, R.L.; BARROS, W.I.T.S.; SILVA, M.G.L.; ALMEIDA, E.A. Diagnóstico acerca de concepções sobre insetos expressas por alunos do ensino fundamental II. Atas do VIII Encontro Nacional de Pesquisa em Educação em Ciências - ENPEC, resumo RI49-2, 2012.

LOPES, P.P.; FRANCO, I.I.; OLIVEIRA, L.R.M.; SANTANA-REIS, V.G. Inseto nas escolas: desvendando o mundo dos insetos para as crianças. Rev. Ciênc. Ext., v.9, n.3, p.125-134, 2013.

MACÊDO, M.V. O contexto do uso dos insetos como instrumento de ensino na Educação Básica, em Insetos na Educação Básica, vol. Único, Macêdo, M.V. e cols, Rio de Janeiro: ED. Fundação CECIERJ, 2009.

MAGALHÃES, A.P.F; MOHR, A. Como os insetos são levados às escolas: uma análise de livros didáticos de ciências. Revista da SBEnBio, n. 7, p. 838-850, 2014.

MATOS, D.A.S.; JARDILINO, J.R.L. Os conceitos de concepção, percepção, representação e crença no campo educacional: similaridades, diferenças e implicações para a pesquisa. Educação \& Formação, v. I, no 3, p. 20-31, 2016.

MATTHEWS, R.W; FLAGE, L.R.; MATTHEWS, J.R. Insects as teaching tools in primary and secondary education. Annual Review of Entomology, v. 42, p. 269-89, 1997.

MERLEAU-PONTY, M. Signos. Iํㅡ. Ed., ED. Martins Fontes, 199I. 
MINISTÉRIO DA EDCUAÇÃO, Lei de Diretrizes e Bases da Educação Brasileira, disponível em http://www.planalto.gov.br/ccivil_03/Leis/L9394.htm, acesso em 20/o5/2019.

MODRO, A.F.H.; COSTA, M.S.; MAIA, E.; ABURAYA, F.H. Percepção entomólogica por docentes e discentes do município de Santa Cruz do Xingu, Mato Grosso, Brasil. Revista Biotemas, v. 22, $\mathrm{n}^{\mathrm{O}}$ 2, p. 153-159, 2009.

MONTENEGRO, I.F.; ALENCAR, J.B.R.; SILVA, E.F.; LUCENA, R.F.P.; BRITO, C.H. Conhecimento, percepção e uso de animais categorizados como "insetos" em uma comunidade rural do semiárido no estado da Paraíba, Nordeste do Brasil. Gaia Scientia, Ed. Especial Populações Tradicionais, p. 250-270, 2014 .

PERRENOUD, P. Construir as competências desde a escola. Porto Alegre: Ed. ARTMED, I999.

POSEY, D. A. O conhecimento entomológico Kayapó: Etnometodologia e sistema cultural. Anuário Antropológico, v. 8I, p. 109-I2I, 1983.

POSEY, D.A. Temas e inquirições em etnoentomologia: algumas sugestões quanto à geração de hipóteses. Boletim do Museu Paraense Emilio Göeldi, Belém, v. 3, no 2, p. 99-134, 1987.

SANTOS, J.R.L.S.; THOMAS, S.E.O.; DORVAL, A.; PASA, M.C. A etnoentomologia na comunidade Mata Cavalo de Baixo em Nossa Senhora do Livramento, MT, Brasil. Biodiversidade, v. 14, no 2, p. 84-92, 2015 .

SANTOS-FITA, D.; COSTA NETO, E. As interações entre os seres humanos e os animais: a contribuição da etnozoologia. Biotemas, v. 20, no 4, p. 99-110, 2007.

SILVA, T. F. P.; COSTA NETO; E. M. Percepção de insetos por moradores da comunidade Olhos D’Água, município de Cabaceiras do Paraguaçu, Bahia, Brasil. Boletín de la Sociedad Entomológica Aragonesa, v. 35, p. 261-268, 2004.

SILVA-JÚNIOR, A.P.; LIMA, L.C.M.; SOUZA-JÚNIOR, J.D.A.; RODRIGUES, H.A. \& VASCONCELOS, S.D. Biofilia e Bem-estar Animal: Percepção e Posicionamento de Universitários de Pernambuco. Sitientibus Série Ciências Biológicas, v. 8, n. I, p. 124-130, 2008.

SOUSA, R.G.; OLIVEIRA, G.G.; TOSCHI, M.S.; CUNHA, H.F. Meio ambiente e insetos na visão de educandos de 6ㅇ e 8o ano de escolas públicas em Anápolis - GO. Ambiente e Educação, v. 18, no 2, p.59-8I, 2013.

SOUZA, A.M.; PEREIRA, A.C.F.; MOURA, J.D.P. Aprendizagem significativa e representações cartográficas: ideias e práticas para um ensino de geografia contextualizado no cotidiano. Revista Formação, v. 25, no 44, p. 75-94, 2018.

TRINDADE, O.S.N; SILVA JÚNIOR, J.C.; TEIXEIRA, P.M.M. Um estudo das representações sociais de estudantes do ensino médio sobre os insetos. Revista Ensaio, v. 14, no 3, p.37-50, 2012. 